\title{
Integrated Data Processing for Multi-Satellite Missions and Recovery of Marine Gravity Field
}

\author{
Motao Huang ${ }^{1, *}$, Guojun Zhai ${ }^{1}$, Yongzhong Ouyang ${ }^{1,2}$, Xiuping Lu ${ }^{1,3}$, Chuanyong Liu ${ }^{1}$, and Rui Wang ${ }^{1,3}$ \\ ${ }^{1}$ Tianjin Institute of Hydrographic Surveying and Charting, Tianjin, China \\ ${ }^{2}$ Institute of Surveying and Mapping, Wuhan University, Wuhan, China \\ ${ }^{3}$ Naval University of Engineering, Wuhan, China
}

Received 15 November 2006, accepted 8 June 2007

\begin{abstract}
In order to eliminate the inconsistency of the existing data from multi-satellite missions, we propose a new method for optimal combination of altimeter data. In our data management system, the crossover adjustment is modified to two-step processing based on the a posteriori compensation theory of error; i.e., the crossover adjustment of condition equations is made in the first step, and the filtering and prediction of adjustment corrections done along each single pass in the second step. Using the new approach can simplify greatly the computational procedure of crossover adjustment, and the stability and reliability of its solution can be expected. The new method can be used for both local and global crossover adjustment problems. Finally, a practical altimeter dataset from Geosat, ERS-1, ERS-2, and TOPEX/POSEIDON (T/P) is used as a case study to prove the efficiency of the integrated data processing method.
\end{abstract}

Key words: Satellite altimetry, Data processing, Crossover adjustment, Gravity anomalies

Citation: Huang, M., G. Zhai, Y. Ouyang, X. Lu, C. Liu, and R. Wang, 2008: Integrated data processing for multi-satellite missions and recovery of marine gravity field. Terr. Atmos. Ocean. Sci., 19, 103-109, doi: 10.3319/TAO.2008.19.1-2.103(SA)

\section{INTRODUCTION}

With the advent of satellite altimetry, the applications of satellite altimetry data have been extensively investigated over recent decades. In the geodetic applications of satellite altimetry, it is shown that this space technique not only allows mapping and monitoring of a major part of the Earth's surface, but it also contributes to essential improvements in the understanding of the Earth's gravity field. Mapping of the sea surface is the most obvious geodetic application. In particular geodetic missions provide a spatial resolution that allows for estimation of mean sea surface heights on a $2^{\prime} \times 2^{\prime}$ grid. Many mean sea surface height models have been developed in the recent years (Bosch 2004). Recovering gravity information from multi-satellite missions' data is another one of the major applications of satellite altimetry. This work was first demonstrated with Seasat data by Haxby et al. (1983). Numerous applications followed: McAdoo and Marks (1992a, b), Sandwell and Smith (1997), Hwang et al. (1998) and Anderson et al. (2000, 2001).

\footnotetext{
* Corresponding author

E-mail:Zhaigj@163.com
}

A general problem in recovering gravity anomalies from the geodetic missions is that the level of neighboring profiles, measured at different epochs is considerably affected by sea level variability (Bosch 2004). The required slope information is thus corrupted by sea level variation and would be transformed to noisy gravity anomalies if no special care is taken in regards to sea level variability. Data processing has been continuously improved by updated altimeter corrections, outlier detection, filtering and retracking of altimeter data. It is well-known that the quality of measurements as well as their spatial resolution and density from different altimeter missions varies considerably. In order to use all existing data for recovering gravity anomalies, many methods have been proposed for optimal combination of altimeter data. Crossover adjustment is a typical procedure for integrated data processing of multi-satellite missions. In this paper, we will use such a procedure, but adopt a very efficient computational strategy in crossover adjustment. In our data management system, the crossover adjustment is modified to two-step processing based on the a posteriori compensation theory of error (Li 1988); i.e., 
the crossover adjustment of condition equations is made in the first step, and the filtering and prediction of adjustment corrections done along each single pass in the second step. The new approach can simplify greatly the computational procedure of crossover adjustment, which can be used for both local and global crossover adjustment problems. In this study, we have used the altimeter data from Geosat, ERS-1, ERS-2, and TOPEX/POSEIDON (T/P) over a regional area of $100^{\circ} \mathrm{E} \leq \lambda \leq 150^{\circ} \mathrm{E}$ and $5^{\circ} \mathrm{S} \leq \varphi \leq 50^{\circ} \mathrm{N}$.

\section{ANALYSIS OF THE EXISTING CROSSOVER ADJUSTMENTS}

In the marine survey, for example, for hydrography, as it relates to marine gravity and magnetic survey, various problems relating to crossover adjustments have been extensively investigated by virtue of the existence of a network structure of marine surveying lines (Prince and Forsyth 1984; Huang 1995; Huang et al. 1999; Liu et al. 2004). The crossover adjustment technique relies on the principle, that two measurements at the same point are used to calibrate measurement equipment or to determine corrections to measurements. Especially, many satellite measurement arrangements with intersection points between the ascending and descending tracks allow for the application of this technique. From the early days of altimetry to nowadays, the radial orbit error has been regarded as one of the dominant sources of errors affecting altimeter data. And the crossover adjustment technique has been thought as one of the most efficient methods for minimizing crossover errors. It is wellknown that the radial orbit error can be sufficiently modeled by either a time- or a distance-dependent polynomial as follows (Wangner 1985; Rummel 1993):

$\Delta r=x_{0}+x_{1} \sin \mu+x_{2} \cos \mu \quad$ (for long tracks)

$\Delta r=x_{0}+x_{1} \mu \quad$ (for middle-long tracks)

$\Delta r=x_{0} \quad$ (for short tracks)

where $x_{0}, x_{1}$, and $x_{2}$ represent unknown polynomial coefficients; $\mu$ is the time- or distance-dependent parameter. Using low degree polynomials as error models results in an overdetermined equation system and a least squares adjustment procedure can be applied. However, for the crossover adjustment, since only differences of measurements (i.e., sea surface height differences at crossover points of the ascending and descending tracks) are used as observations and since these differences are invariant with respect to certain transformations, the corresponding adjustment problem is singular. That is to say, in such an adjustment system, only relative parameters can be determined uniquely. If parameters with absolute information such as bias and tilt parameters have to be predicted, the resulting normal equations are well-known to be singular and some additional constraints have to be fixed to solve this adjustment problem. In practice there exist three ways to overcome the rank deficiency (Schuh 1998):

(1) Master arcs approach - a number of arbitrary unknowns (some tracks) are fixed.

(2) Free adjustment - with the help of a generalized inverse, an unconstrained solution can be determined and after this step constraints are used to fit the system to a welldefined reference frame. The pseudoinverse solution combines these two steps within one procedure.

(3) Combined solution - the third possibility to overcome the singular problem is to introduce the reference frame as pseudo-observations and to stabilize with this information about the whole system. A special target function with a proper weighting between real observations and pseudo-observations allows for solving this hybrid system.

It should be mentioned that the first two approaches don't affect the observations and the observational residuals. Only the fitting of a so-called free surface is affected by the choice of the additional parameters. The pseudo-observations within the combined solution, in turn, are constraining the configuration of the real observations. Therefore, one has to be very careful when it comes to choosing the weight factor.

According to the preceding analysis and discussion, it can be seen that crossover adjustment is a special adjustment system. Its computational procedure is heavy and complicated. That is true even more so for the local and global crossover adjustment problem of the irregular network. Additionally, since, in the adjustment system, the neighboring equations share a part of the unknown parameters in one equation, there exists a function relation between the neighboring equations. Therefore, we have to solve all the equations in an integrated way. Within this study, our purpose is to simplify the procedure of solving the equations. Here we propose an approximate approach to deal with the singular crossover adjustment problem. The key to the modified method is to divide the solution procedure into two steps. First, a conventional crossover point adjustment is carried out using the condition adjustment method; and then filtering and predicting of observational corrections are done along each track.

\section{CONDITION ADJUSTMENT AT CROSSOVER POINTS}

As we know, the altimeter observation $h$ can be split up into a track-independent part $h_{0}$, only depending on the 
measurement location, and a residual part $\Delta h$, which is track dependent. The residual part $\Delta h$ consists of a part due to the systematic error $\delta h$ and the stochastic measurement inaccuracy $\Delta$. That is:

$h=h_{0}+\Delta h=h_{0}+\delta h+\Delta$

By introducing the difference of two sea surface height observations at the crossover point of ascending track $i$ and descending track $j$ as the crossover observation, we can define an error equation as:

$v_{i j}^{a}-v_{i j}^{d}=h_{i j}^{a}-h_{i j}^{d}=d_{i j}$

where $h_{i j}^{a}-h_{i j}^{d}=d_{i j}$ is the discrepancy at the crossover point $p(i, j)$; the right superscript $a$ indicates ascending tracks, and the right superscript $d$ indicates descending tracks. As for a survey network constructed by $M$ ascending tracks and $N$ descending tracks, the error equations can be expressed in matrix notation as follows:

$B V-D=0$

where $V$ represents the correction vector including the signal (systematic error) and noise (random error) parts; $B$ is the coefficient matrix which consists of 1 and $-1 ; D$ indicates the discrepancy vector. The least square solution of Eq. (6) is:

$V=P^{-1} B^{T}\left(B P^{-1} B^{T}\right)^{-1} D$

The cofactor matrix is:

$Q_{V}=P^{-1} B^{T}\left(B P^{-1} B^{T}\right)^{-1} B P^{-1}$

where $P$ is the weighting matrix of discrepancy observations. Suppose the sea surface height observations to be independent along each track, Eq. (7) can be further rewritten as:

$v_{i j}^{a}=p_{i j}^{d} d_{i j} /\left(p_{i j}^{a}+p_{i j}^{d}\right)$

$v_{i j}^{d}=-p_{i j}^{a} d_{i j} /\left(p_{i j}^{a}+p_{i j}^{d}\right)$

where $p_{i j}^{a}$ and $v_{i j}^{a}$ represent the weight factor of observation and its correction along ascending track $i$ at crossover point $p(i, j)$, respectively; $p_{i j}^{d}$ and $v_{i j}^{d}$ represent the weighting factors of observation and its correction along descending track $j$ at crossover point $p(i, j)$, respectively.

\section{FILTERING AND PREDICTING ALONG TRACKS}

According to the modern adjustment theory (Li 1988), after the observational correction vector is calculated from Eq. (7), it can be further considered as a new kind of observations and then be filtered using an error model similar to Eqs. (1), (2), or (3). As mentioned above, in this study our aim is to illustrate the crossover adjustment in a more extensive sense; i.e., the compensation of systematic errors in satellite altimetry. In our opinion, the compensation of systematic errors is, in principle, a special filtering and predicting problem which intends to separate signals (systematic errors) from observations (i.e., differences at crossover points) by weighting the uncertainty of noises (random errors). Taking into account the fact that the amplitude of orbit error is, now, almost the same as that of influence of other physical and geometric uncertainties such as the inconsistency in the satellite orbit frame, and the additional errors caused by residual ocean variation and various physical corrections, a reasonable error model is constructed in this paper to illustrate the change of signals, with which the filtering and prediction of crossover adjustment corrections are done along each single track in our new computational strategy. And finally, the compensation of systematic errors in satellite altimetry is realized.

It is clear from the preceding error analysis that the performance of the errors from satellite altimetry appears mainly to have a systematic influence on measurements. The combined effect of the errors will vary in very complicated ways. It may consist of linear, periodic, and irregular trends. It means that the temporal or spatial variation model of errors above can take a variety of forms. In the case study here, we have carried out a series of tests using general polynomial and trigonometric polynomial error models, and made a comparison between them. It has been shown that a combined model of general and trigonometric polynomials is more advantageous in describing change of systematic errors in satellite altimetry. This model can be expressed as follows:

$\delta h=f(t)=a_{0}+a_{1} t+\sum_{i=1}^{n}\left(b_{i} \cos i \omega t+c_{i} \sin i \omega t\right)$

where $n$ is a positive integer; $\omega$ represents the angular frequency corresponding to a period covering a surveying track; i.e., $\omega=2 \pi /\left(t_{e}-t_{b}\right) ; t_{e}$ and $t_{b}$ are the end and beginning times of a surveying track, respectively; $a_{0}, a_{1}, b_{i}$ and 
$c_{i}(i=1, \ldots, n)$ are the unknown model parameters to be evaluated. The error model listed above consists of two parts. The first characterizes the linear trend as systematic errors. The second indicates the periodic trend. The intention of choosing Eq. (11) as the error model is to embrace the influence of a variety of systematic errors in addition to the radial orbit error. And it is expected to appropriately characterize the integrated effect of different disturbing factors. In practical application, the parameter $n$ is determined with the length of the track. By our experience, here $n$ is proposed to be $1 \sim 2$ for a short track, $3 \sim 5$ for a middle-long track, and $6 \sim 8$ for a long track. Furthermore, the significance test of model parameters $\left(a_{0}, a_{1}, b_{i}\right.$, and $\left.c_{i}\right)$ can be done in the same way as Huang et al. (1999). In an adjustment problem, the error model will approximate the physical and geometric property of the problem in case it is properly chosen. The adjustment results can show the performance of our empirically chosen model to the observations. This will be illustrated furthermore in the case study of this paper.

After condition adjustment at crossover points, a new error equation can be constructed with error model (11) at each crossover point as follows:

$v=f(t)+\Delta$

And its matrix form is:

$V=A X+U$

where $V$ represents the new "observation" vector obtained from the preceding condition adjustment; $U$ is the correction vector of $V ; A$ and $X$ represent the coefficient matrix of error equation and the corresponding unknown vector of error model, respectively. The least square solution of Eq. (13) is:

$X=\left(A^{T} P_{V} A\right)^{-1} A^{T} P_{V} V$

where $P_{V}$ is the weight matrix of "observation" vector $V$. With the error model obtained from the adjustment (i.e., filtering) results above, the systematic error at each observational point between the crossover points along each track can be interpolated appropriately according to its observational time. This step can be thought to be a prediction.

It can be seen from Eq. (8) that the weight matrix $P_{V}$ of "observation" vector $V$ is a special sparse matrix, which consists of some unit matrixes degree to 4 , in the case that the sea surface height observations is independent and there is equal accuracy along each track. It is to say that, in that case, an "observation" along each ascending track is related only to one "observation" from descending tracks. In other words, an "observation" along each descending track is also related only to one "observation" from ascending tracks. If neglecting such weak statistical correlation of errors between ascending and descending tracks, the "observations" from each track (both ascending and descending tracks) can be processed separately, independent of the other tracks. This is just as we expected at the beginning when the twostep computational strategy was suggested. Compared to the rigorous overall adjustment method, although theoretically, the two-step processing approach cannot be, in effect, better than the former with a reasonable weighting of parameters, the latter has simplified the computational procedure of crossover adjustment greatly and rank deficiency will never arise. And, therefore, the adjustment results of the latter should be more stable and reliable. It is more suitable to integrated data processing for multi-satellite missions as illustrated in this study.

\section{A CASE STUDY FOR MULTI-SATELLITE ALTIMETER DATA PROCESSING}

As mentioned above, here we have used the altimeter data from Geosat, ERS-1,ERS-2, and TOPEX/POSEIDON $(\mathrm{T} / \mathrm{P})$ over a regional area of $100^{\circ} \mathrm{E} \leq \lambda \leq 150^{\circ} \mathrm{E}$ and $5^{\circ} \mathrm{S} \leq$ $\varphi \leq 50^{\circ} \mathrm{N}$ as a case study to show the performance of the two-step processing approach. In order to eliminate the inconsistency of data from the single satellite mission, in the first stage of integrated data processing, a auto-crossover adjustment using the two-step method within a single-satellite mission is carried out for the above 4 satellites. Furthermore, because of factors such as orbit error and inconsistency in the satellite orbit frame, the sea surface heights (SSHs) from different satellite missions need to be adjusted to a 'standard' surface. In this regard, the SSHs from the auto-crossover adjustment of T/P have served as a standard surface in the second stage of integrated data processing because of its highly accurate orbit. That is called as cocrossover adjustment for dual-satellite missions. It is done also using the two-step method in this study. Table 1 shows the statistics of crossover differences before and after autocrossover adjustment. The statistics of crossover differences between $\mathrm{T} / \mathrm{P}$ and other satellites before and after co-crossover adjustment are given in Table 2 .

Making a comparison between before and after adjustments in Table 1, it can be seen that an expected result has been obtained by using the two-step method. The RMS crossover differences from before and after auto-crossover adjustment are $\pm 5 \sim \pm 25$ and $\pm 2 \sim \pm 10 \mathrm{~cm}$, indicating the new computational strategy can improve the internal accuracy of altimeter data from a single satellite mission. The results before co-crossover adjustment in Table 2 show that there is a systematic bias between $\mathrm{T} / \mathrm{P}$ and other satellite altimeter data. It is just because there exists an inconsistency between 
Table 1. Statistics of crossover differences (in $\mathrm{cm}$ ) before and after auto-crossover adjustment.

\begin{tabular}{|c|c|c|c|c|c|c|c|c|c|}
\hline \multirow{2}{*}{ Satellite } & \multirow{2}{*}{ No. point } & \multicolumn{4}{|c|}{ Before adjustment } & \multicolumn{4}{|c|}{ After adjustment } \\
\hline & & Min & Max & Mean & RMS & Min & $\operatorname{Max}$ & Mean & RMS \\
\hline ERS-1 & 1383 & -60 & 46 & 1.6 & \pm 14.4 & -36 & 28 & 0.10 & \pm 6.0 \\
\hline ERS-2 & 1423 & -74 & 87 & 0.7 & \pm 8.4 & -28 & 46 & -0.01 & \pm 4.9 \\
\hline Geosat/ERM & 490 & -50 & 43 & -4.2 & \pm 13.7 & -24 & 20 & 0.00 & \pm 5.2 \\
\hline Geosat/GM & 133600 & -180 & 232 & -9.0 & \pm 24.9 & -90 & 111 & -0.03 & \pm 10.4 \\
\hline $\mathrm{T} / \mathrm{P}$ & 156 & -17 & 14 & -0.9 & \pm 4.5 & -11 & 8 & 0.07 & \pm 2.2 \\
\hline
\end{tabular}

Table 2. Statistics of crossover differences (in $\mathrm{cm}$ ) between T/P and other satellites before and after co-crossover adjustment.

\begin{tabular}{|c|c|c|c|c|c|c|c|c|c|}
\hline \multirow{2}{*}{ Satellite } & \multirow{2}{*}{ No. point } & \multicolumn{4}{|c|}{ Before adjustment } & \multicolumn{4}{|c|}{ After adjustment } \\
\hline & & Min & Max & Mean & RMS & Min & $\operatorname{Max}$ & Mean & RMS \\
\hline ERS-1 & 1243 & -54 & 86 & 22.9 & \pm 26.8 & -32 & 37 & 0.03 & \pm 5.5 \\
\hline ERS-2 & 1214 & -7 & 119 & 25.8 & \pm 29.9 & -36 & 36 & -0.03 & \pm 5.1 \\
\hline Geosat/ERM & 542 & -72 & 94 & 16.0 & \pm 20.9 & -64 & 47 & -0.01 & \pm 6.4 \\
\hline Geosat/GM & 5551 & -126 & 139 & 16.0 & \pm 22.0 & -49 & 41 & 0.01 & \pm 5.6 \\
\hline
\end{tabular}

T/P and other satellite orbit frames. The systematic bias has been eliminated after co-crossover adjustment. Compared to the RMS crossover differences of $\pm 21 \sim \pm 30 \mathrm{~cm}$ from before co-crossover adjustment, an improved accuracy of $\pm 5 \sim \pm 6 \mathrm{~cm}$ has been obtained after co-crossover adjustment. It means that we have arrived at the goal of unifying all multi-satellite altimeter data in the frame of T/P. Figure 1 shows the adjusted SSHs over the studied area.

\section{RECOVERY OF MARINE GRAVITY FIELD FROM SATELLITE ALTIMETER DATA}

In order to evaluate the modified method proposed in this paper, we have gone a step further to recover marine gravity anomalies using all the multi-satellite altimeter data mentioned above. Results are then compared with shiptrack gravity data. After having finished the auto- and cocrossover adjustments using the two-step method, the sea surface topography of EGM96 model to degree and order 20 is subtracted from the adjusted SSHs before generating the deflections of the vertical. On the basis of that, we used the least-squares collocation method proposed by Hwang et al. (1998) to grid the deflections of different azimuths into the north-south and west-east components at a $2^{\prime} \times 2^{\prime}$ interval, which are then used to compute the gravity anomalies using the inverse Vening Meinesz formula (see Hwang 1998) by the 1-D FFT method. Figure 2 shows the derived gravity anomalies over the studied area. Finally, the quality of the derived gravity anomalies are evaluated by comparison with ship-borne gravity data, which came from numerous cruises dating from 1990 to 2000 over the China Sea. It is believed that the accuracy of the ship anomaly is at the level of 1 to 3 mgal. Before comparison, the gravity anomalies from the altimeter-derived grid are interpolated to each ship anomaly location using the weighted average method. The comparisons are made at all (1497080) stations. The statistics of comparisons are listed in Table 3.

Table 3 indicates that there exists a significant bias in all the altimeter-derived/ship anomaly comparisons, which ranges from -0.1 to $-4.7 \mathrm{mgal}$. The cause of this may be related to the errors remaining in the ship gravity data or in the reference geopotential model. The RMS comparison differences ranges from \pm 4.79 to $\pm 8.57 \mathrm{mgal}$. These results are comparable with those from Sandwell and Smith (1997), Hwang et al. (1998), and Anderson et al. (2000, 2001). In Sandwell and Smith (1997), the RMS difference between the satellite-derived and the ship-measured gravity anomalies over 12 areas is from \pm 5.91 to \pm 15.14 mgal. And in Hwang et al. (1998), RMS agreements of \pm 5.13 to \pm 14.26 are obtained in the same areas. It is shown that the integrated data processing procedure suggested in this paper is efficient and reliable. 


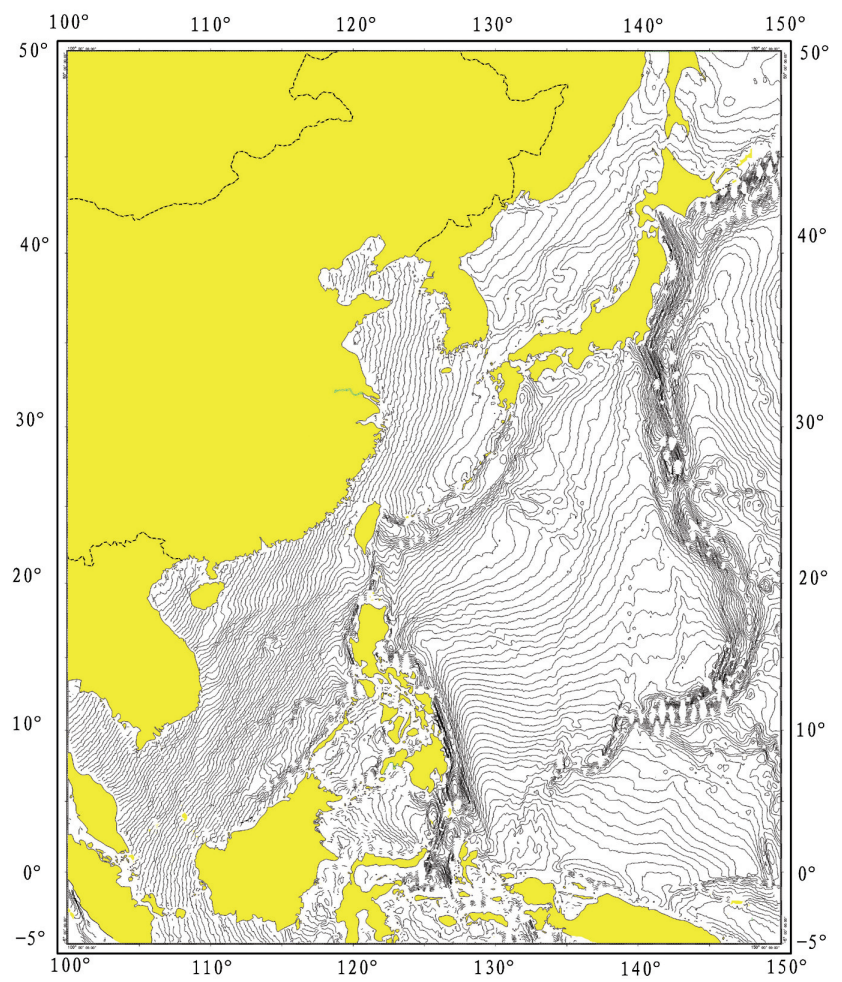

Fig. 1. The contour map of adjusted SSHs over the studied area with a contour interval of $1 \mathrm{~m}$.

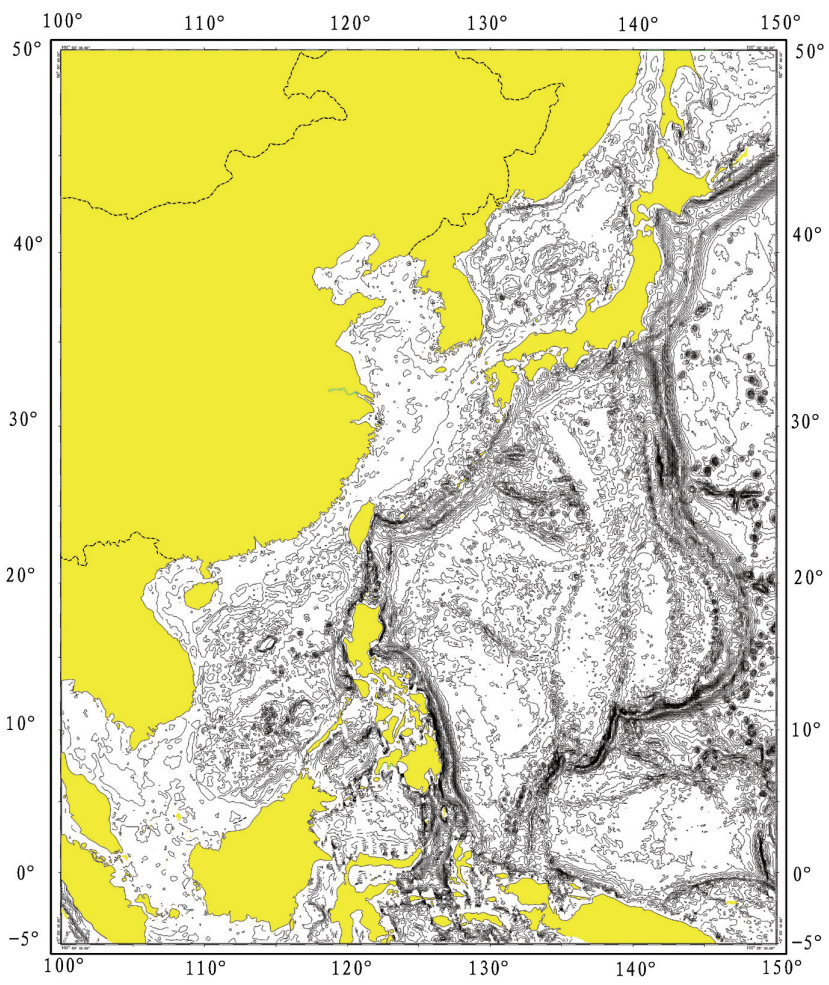

Fig. 2. The contour map of derived gravity anomalies over the studied area with a contour interval of $20 \mathrm{mgal}$.

Table 3. Statistics of differences (in mgal) between ship-measured and satellite-derived gravity anomalies over the China Sea.

\begin{tabular}{|c|c|c|c|c|c|c|}
\hline \multirow{2}{*}{$\begin{array}{l}\text { Years of } \\
\text { data }\end{array}$} & \multirow[t]{2}{*}{ Area of data locations } & \multirow{2}{*}{$\begin{array}{c}\text { Number of } \\
\text { points }\end{array}$} & \multicolumn{2}{|c|}{$\begin{array}{c}\text { Amplitude of } \\
\text { gravity variation }\end{array}$} & \multirow{2}{*}{$\begin{array}{l}\text { Mean of } \\
\text { Diff. }\end{array}$} & \multirow{2}{*}{$\begin{array}{l}\text { RMS of } \\
\text { Diff. }\end{array}$} \\
\hline & & & Min & $\operatorname{Max}$ & & \\
\hline 1990 & $8^{\circ} \sim 12^{\circ} \mathrm{N} ; 111^{\circ} \sim 115^{\circ} \mathrm{E}$ & 3070 & -33 & 88 & -3.38 & 8.25 \\
\hline 1991 & $8^{\circ} \sim 16^{\circ} \mathrm{N} ; 113^{\circ} \sim 117^{\circ} \mathrm{E}$ & 2545 & -427 & 481 & -2.90 & 8.57 \\
\hline 1993 & $12^{\circ} \sim 15^{\circ} \mathrm{N} ; 113^{\circ} \sim 116^{\circ} \mathrm{E}$ & 3833 & -34 & 136 & -3.54 & 5.77 \\
\hline 1994 & $9^{\circ} \sim 11^{\circ} \mathrm{N} ; 110^{\circ} \sim 114^{\circ} \mathrm{E}$ & 2532 & -32 & 84 & -3.01 & 6.49 \\
\hline 1995 & $11^{\circ} \sim 12^{\circ} \mathrm{N} ; 110^{\circ} \sim 114^{\circ} \mathrm{E}$ & 2492 & -45 & 36 & -3.96 & 5.87 \\
\hline 1996 & $12^{\circ} \sim 14^{\circ} \mathrm{N} ; 110^{\circ} \sim 114^{\circ} \mathrm{E}$ & 2407 & -216 & 60 & -3.26 & 5.29 \\
\hline 1997 & $11^{\circ} \sim 15^{\circ} \mathrm{N} ; 110^{\circ} \sim 114^{\circ} \mathrm{E}$ & 13874 & -56 & 92 & -0.99 & 5.61 \\
\hline 1998 & $14^{\circ} \sim 17^{\circ} \mathrm{N} ; 112^{\circ} \sim 115^{\circ} \mathrm{E}$ & 9681 & -124 & 87 & -1.89 & 7.18 \\
\hline 1999A & $15^{\circ} \sim 18^{\circ} \mathrm{N} ; 114^{\circ} \sim 118^{\circ} \mathrm{E}$ & 56936 & -100 & 146 & -3.68 & 6.66 \\
\hline 1999B & $17^{\circ} \sim 20^{\circ} \mathrm{N} ; 113^{\circ} \sim 116^{\circ} \mathrm{E}$ & 63314 & -63 & 66 & -2.46 & 5.01 \\
\hline $2000 \mathrm{~A}$ & $16^{\circ} \sim 20^{\circ} \mathrm{N} ; 116^{\circ} \sim 119^{\circ} \mathrm{E}$ & 58438 & -80 & 179 & -1.64 & 6.65 \\
\hline 2000B & $17^{\circ} \sim 20^{\circ} \mathrm{N} ; 117^{\circ} \sim 120^{\circ} \mathrm{E}$ & 60786 & -137 & 65 & -4.04 & 5.75 \\
\hline $2001 \mathrm{~A}$ & $7^{\circ} \sim 10^{\circ} \mathrm{N} ; 110^{\circ} \sim 116^{\circ} \mathrm{E}$ & 58946 & -116 & 205 & -4.71 & 7.30 \\
\hline 2001B & $5^{\circ} \sim 9^{\circ} \mathrm{N} ; 108^{\circ} \sim 110^{\circ} \mathrm{E}$ & 10841 & -73 & 61 & -4.13 & 5.80 \\
\hline $2002 \mathrm{~A}$ & $12^{\circ} \sim 16^{\circ} \mathrm{N} ; 117^{\circ} \sim 119^{\circ} \mathrm{E}$ & 305103 & -70 & 112 & -3.52 & 5.95 \\
\hline $2002 B$ & $22^{\circ} \sim 25^{\circ} \mathrm{N} ; 117^{\circ} \sim 120^{\circ} \mathrm{E}$ & 184756 & -19 & 54 & -0.12 & 7.65 \\
\hline $2003 \mathrm{~A}$ & $17^{\circ} \sim 18^{\circ} \mathrm{N} ; 109^{\circ} \sim 110^{\circ} \mathrm{E}$ & 338441 & -42 & 62 & -2.13 & 5.26 \\
\hline 2003B & $25^{\circ} \sim 29^{\circ} \mathrm{N} ; 120^{\circ} \sim 123^{\circ} \mathrm{E}$ & 319085 & -33 & 70 & -0.32 & 4.79 \\
\hline
\end{tabular}




\section{CONCLUSIONS}

This article has concentrated on integrated data processing for multi-satellite missions using a modified crossover adjustment, i.e., two-step method, and the recovery of marine gravity anomalies. A comparison between altimetry-derived gravity anomalies and ship-borne data has been made. And the compared results are satisfactory. It should be pointed out, however, that such results are obtained here only over open ocean. More work should be done with altimeter data over shallow waters if we wish to obtain results over shallow water comparable in quality with those over the open ocean; see, e.g., Deng et al. (2002) and Hwang et al. (2004).

Acknowledgements The authors wish to express their gratitude to Prof. C. Hwang and the anonymous reviewers for their valuable comments and recommendations as well as the English corrections. Without their help the manuscript could not have been so improved.

\section{REFERENCES}

Anderson, O., P. Knudsen, S. Kenyon, and R. Trimmer, 2000: The KMS2001 Global Mean Sea Surface and Gravity Field. Poster, IAG 2001 General Assembly, "Vistas for Geodesy in the new Millenium", 2 - 7, September 2001, Budapest, Ungary.

Anderson, O., P. Knudsen, and R. Trimmer, 2001: The KMS99 Global Marine Gravity Field - Improvements and Accuracy Assessment. EGS General Assembly, Nice.

Bosch, W., 2004: Geodetic application of satellite altimetry. In: Hwang, C., C. Shum, and J. Li (Eds.), Satellite Altimetry for Geodesy, Geophsics and Oceanography, IAG Symposia, 126, Springer, 3-21.

Deng, X. L., A. Featherstone, C. Hwang, and P. Berry, 2002: Estimation of contamination of ERS-2 and POSEIDON satellite radar altimetry close to the coasts of Australia. Mar. Geodesy, 25, 249-271.

Haxby, W. F., G. D. Karner, J. L. La Brecque, and J. K. Weissel, 1983: Digital images of combined oceanic and continental data sets and their use in tectonic studies. EOS Trans. AGU, 64, 995-1004.

Huang, M. T., 1995: Marine gravity surveying line system adjustment. J. Geodesy, 70, 158-165.
Huang, M. T., Z. Guan, G. J. Zhai, and Y. Z. Ouyang, 1999: On the compensation of systematic errors in marine gravity measurements. Mar. Geodesy, 22, 183-194.

Hwang, C., 1998: Inverse vening meinesz formula and deflection-geoid formula: Applications to the predictions of gravity and geoid over the South China Sea. J. Geodesy, 72, 304-312.

Hwang, C., E. C. Kao, and B. Parson, 1998: Global derivation of marine gravity anomalies from SEASAT, Geosat, ERS-1, and TOPEX/POSEIDON altimeter data. Geophys. J. Int., 134, 449-459.

Hwang, C., S. Hsu, and X. L. Deng, 2004: Marine gravity anomaly from satellite altimetry: A comparison of methods over shallow waters. In: Hwang, C., C. Shum, and J. Li (Eds.), Satellite Altimetry for Geodesy, Geophsics and Oceanography, IAG Symposia, 126, Springer, 59-66.

Li, D. R., 1988: Error Processing and Reliability Theory. Publishing House of Surveying and Mapping, Beijing. (in Chinese)

Liu, Y. C., M. S. Li, F. M. Xiao, J. Y. Bao, and M. T. Huang, 2004: A method for detecting and adjusting systematic errors of singlebeam sounding data acquired in a grid pattern. Int. Hydrogr. Rev., 5, 34-53.

Mcadoo, D. C., and K. M. Marks, 1992a: Resolving marine gravity with ERS-1 satellite altimetry. Geophys. Res. Lett., 19, 2271-2274.

Mcadoo, D. C., and K. M. Marks, 1992b: Gravity field of the southern ocean from geosat data. J. Geophys. Res., 97, 3247-3260.

Prince, R. A., and D. W. Forsyth, 1984: A simple objective method for minimizing crossover errors in marine gravity data. Geophysics, 49, 1070-1083.

Rummel, R., 1993: Principle of satellite altimetry and elimination of radial orbit errors. In: Rummel, R., and F. Sanso (Eds.), Satellite Altimetry in Geodesy and Oceanography, Springer, 189-241.

Sandwell, D. T., and W. H. F. Smith, 1997: Marine gravity anomaly from geosat and ERS-1 satellite altimetry. $J$. Geophys. Res., 102, 10039-10054.

Schuh, W. D., 1998: Crossover adjustment using array algebra. Int. Geoid Serv. Bull., 7, 38-51.

Wangner, C. A., 1985: Radial variations of a satellite orbit due to gravitational errors, implications for satellite altimetry. J. Geophys. Res., 90, 3027-3036. 